\title{
Eleventh Hypertension Research Award for authors of outstanding papers in Hypertension Research
}

\author{
Toshihiko Ishimitsu Editor-in-Chief ${ }^{1}$
}

Published online: 26 October 2020

(C) The Japanese Society of Hypertension 2020

Japanese Society of Hypertension (JSH) has announced the winners of the 11th Hypertension Research Award at the general meeting on October 25, 2020 in Tokyo, Japan. This award was established in 2010 to recognize significant contributions of researchers to the advancement of researches in hypertension and related studies. Among the first or main authors of the articles published in Hypertension Research, official journal of JSH, from April 2019 (Vol. 42, No. 4) to March 2020 (Vol. 43 , No. 3) the journal's editorial committee members selected following winners.

\section{Hypertension Research Award of Excellence}

Dr Takeshi Iyonaga, Department of Cardiovascular Medicine, Kyushu University Graduate School of Medical Sciences, Fukuoka, Japan.

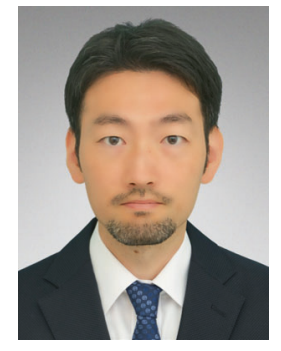

For contribution of 'Brain perivascular macrophages contribute to the development of hypertension in stroke-prone spontaneously hypertensive rats via sympathetic activation.' Vol. 43, No. 2, pp 99-110. https://doi.org/10.1038/s41440019-0333-4.

https://rdcu.be/b6Q62

In this animal study, apoptosis of brain perivascular macrophages was chemically induced in stroke-prone spontaneously hypertensive rats resulting in reductions of central sympathetic neuronal activity and blood pressure. The authors also indicated that sympathetic nerve activation

Toshihiko Ishimitsu isimitu@dokkyomed.ac.jp

1 Department of Nephrology and Hypertension, Dokkyo Medical University, Mibu, Tochigi, Japan by brain perivascular macrophages may be mediated by interleukin-1 $\beta$.

\section{Hypertension Research Award}

Dr Azusa Shima, Department of Public Health, Shiga University of Medical Science, Shiga, Japan.

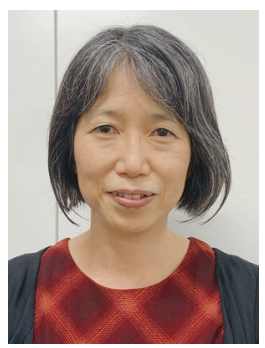

For contribution of 'Relationship of household salt intake level with long-term all-cause and cardiovascular disease mortality in Japan: NIPPON DATA80.' Vol. 43, No. 2, pp 132-139. https://doi.org/10.1038/s41440-019-0349-9.

https://rdcu.be/b6Q66

This epidemiological study showed the results of longterm (24 years) follow-up survey of Japanese cohort as to the influence of salt intake on mortality and fatal cardiovascular events. The authors evaluated the salt intake of participants at house-hold level and showed the $2 \mathrm{~g} / 1000 \mathrm{kcal}$ increase in salt intake was associated with significant increases in all-cause and cardiovascular mortalities. 


\section{Hypertension Research Award}

Dr Akihide Ohkuchi, Department of Obstetrics and Gynecology, Jichi Medical University School of Medicine, Shimotsuke-shi, Tochigi, Japan.

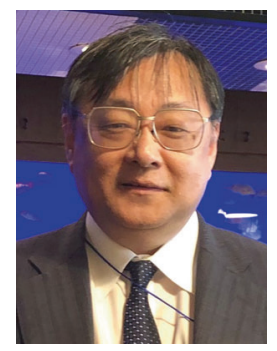

For contribution of 'Temporary hypertension and white coat hypertension in the first trimester as risk factors for preeclampsia.' Vol. 42, No. 12, pp 2002-2012. https://doi.org/ 10.1038/s41440-019-0307-6.

\section{https://rdcu.be/b6Q7a}

This was a retrospective cohort study involving pregnant women receiving regular checkups during pregnancy. The authors classified participants according to blood pressure (BP) level at first trimester and found not only chronic hypertension but also high-normal BP, white-coat hypertension and transient hypertension which normalized at 14-19 weeks were risk factors for developing preeclampsia after 20 weeks.

\section{Compliance with ethical standards}

Conflict of interest Honoraria: TI (Takeda Pharmaceutical); Research fund: TI (Daiichi Sankyo, Torii Pharmaceutical).

Publisher's note Springer Nature remains neutral with regard to jurisdictional claims in published maps and institutional affiliations. 